\title{
Targeted Chemotherapy via Folic Acid Decorated Nanomedicines
}

\author{
Ana Isabel FS ${ }^{1}$, Carballido $\mathrm{AF}^{1,2}$ and Ana Isabel TS $1,2 *$ \\ 1Department of Pharmaceutics and Food Technology, Faculty of Pharmacy, \\ Complutense University of Madrid, Spain \\ ${ }^{2}$ Institute of Industrial Pharmacy, Complutense University of Madrid, Spain
}

Short Communication

Volume 3 Issue 2

Received Date: July 04, 2018

Published Date: July 16, 2018

*Corresponding author: Ana Isabel Torres Suarez, Plaza Ramón y Cajal s/n, Department of Pharmaceutics and Food Technology, Faculty of Pharmacy, Complutense University of Madrid, 28040, Spain, Tel: (+34) 913941735; Email: galaaaa@ucm.es

\section{Abstract}

The development of nanomedicines decorated with ligands specifically recognized by cancer cells is a promising strategy to get a selective location of the antitumor drug at tumor cells, increasing its efficacy and reducing adverse effects. One of the most interesting ligands is folic acid, whose $\alpha$-type-receptors are over expressed in numerous kinds of carcinomas. Several folic acid nanomedicines such as nanoparticles, micelles and liposomes have shown to increase the efficacy of conventional anticancer drugs in gynecological carcinomas, becoming in engaging therapeutics tools in these malignances.

Keywords: Folic acid; Nanomedicine; Tumor targeting; ovarian cancer; Breast cancer; Cervix cancer

\section{Introduction}

A selective localization of antineoplasic drugs at tumor cells level is highly desirable in chemotherapeutic treatments, to get a reduction of drug adverse effects and an improvement of therapeutic efficacy. The use, as carriers of antitumor drugs of nanomedicines (micelles, liposomes, dendrimers and nanoparticles among others) that are decorated with ligands that are selectively recognized by receptors over expressed in the membrane of cancer cells, is one of the most promising strategies to get a targeted chemotherapy $[1,2]$. In this sense, there are numerous molecules that are currently under investigation such as different carbohydrates, folic acid, biotin, transferrin, epidermal growth factor, antibodies, viral proteins or aptamers $[3,4]$.
Folic acid is one of the most promising ligands due to: (i) the overexpression of folate receptor- $\alpha$ (FR- $\alpha$ ) in numerous kinds of tumors including ovarian, breast, kidneys, lung, uterus, and colon carcinomas; showing folic acid a high binding affinity for these receptors $\left(\mathrm{K}_{\mathrm{d}} \sim 10^{10} \mathrm{M}^{-}\right.$ ${ }^{1}$ ); (ii) its low immunogenicity, (iii) it is easy modify and (iv) its low cost $[5,6]$.

This paper focuses on the use of folic acid decorated nanomedicines loaded with conventional anticancer drugs as targeted chemotherapy strategy in gynaecological cancers.

\section{Breast Cancer}

Paclitaxel (PTX) is a common chemotherapeutic agent used in breast cancer treatments. Several authors have 


\section{Advances in Pharmacology and Clinical Trials}

shown that nanosystems loaded with placlitaxel enhance tumor cell sensitivity via folic acid targeting, increasing the cellular uptake of the drug. In this sense, cyclodextrin nanoparticles and liposomes decorated with folic acid and loaded with PTX significantly increased in vitro drug efficacy on ZR75-1 [6] and MCF-7 and MDA-MB-231 cells (FR- $\alpha$ positive) respectively, decreasing $\mathrm{IC}_{50}$ values. In the case of liposomes the $\mathrm{IC}_{50}$ of folate decorated formulations were 2,2 and 11.5 times lower than nondecorated ones for MCF7 and MDA-MB-231 cells respectively. The more significant enhancement in MDAMB-231 cells has been attributed to the major overexpression of FR- $\alpha$ [7]. Finally, folic acid functionalized micelles also improved the inhibition of MCF-7 cell proliferation, comparing to other PTX formulations. While the $\mathrm{IC}_{50}$ of this cells after 72 hours of incubation for free PTX and non-targeted micelles were 14.01 and $11.78 \mathrm{nM}$ respectively, targeted micelles exhibited a significantly lower value of $6.61 \mathrm{nM}$ [8] (Table1). Folic acid conjugation also increased the uptake of lipids nanoparticles co-loaded with docetaxel (PTX analogue) and curcurmin in MCF-7 cells, improving anticancer efficacy. In vivo experiments in rats also demonstrated a less docetaxel accumulation in heart and kidney than conventional formulations, resulting in a toxicity diminution [9].

\section{Ovarian Cancer}

Folic acid targeting has also shown to improve the efficacy of taxanes and other antineplasic drugs in ovarian cancer. Paclitaxel and cisplatin loaded nanogels functionalized with folic acid have reported an increase of the in vitro anticancer activity in A2780 cells (FR- $\alpha$ positive), comparing to non-functionalized formulations and being this improvement attributed to folic acid association. In vivo experiments in tumor xenograft mouse models also proved that these folate conjugated formulations, after intraperitoneal administration, were more effective [10]. Folic acid conjugated liposomes also increased the cytotoxic effect of carboplatin in IGROV1 cells, decreasing the $\mathrm{IC}_{50}$ value from 40 to $13.1 \mu \mathrm{M}$ in free and encapsulated drug respectively. Finally, this effect has also been demonstrated in vivo in mouse models, showing an increase of the survival rate [11] (Table1).

\begin{tabular}{|c|c|c|c|c|c|}
\hline Carcinoma & Nanocarrier & Drug & Cell line & $\mathbf{I C}_{50}$ & Reference \\
\hline \multirow{5}{*}{ Breast } & $\begin{array}{l}\text { Cyclodextrin } \\
\text { nanoparticles }\end{array}$ & Paclitaxel & ZR75-1 T-47D & NA & [6] \\
\hline & \multirow[t]{2}{*}{ Liposomes } & \multirow[t]{2}{*}{ Paclitaxel } & MCF-7 & $\begin{array}{c}\text { Free PTX=660.7 nM Liposomes }=214.1 \\
\text { nM FA-Liposomes=97.6 nM }\end{array}$ & \multirow[t]{2}{*}{ [7] } \\
\hline & & & MDA-MB-231 & $\begin{array}{c}\text { Free PTX=689.3 nM Liposomes }=183.1 \\
\text { nM FA-Liposomes }=15.7 \mathrm{nM}\end{array}$ & \\
\hline & Micelles & Paclitaxel & MCF-7 & $\begin{array}{c}\text { Free PTX }=14.01 \mathrm{nM} \text { Micelles }=11.78 \mathrm{nM} \\
\text { FA-micelles }=6.61 \mathrm{nM}\end{array}$ & [8] \\
\hline & $\begin{array}{c}\text { Lipids } \\
\text { nanoparticles }\end{array}$ & $\begin{array}{l}\text { Docetaxel } \\
\text { Cucurmin }\end{array}$ & MCF-7 & NA & [9] \\
\hline \multirow{3}{*}{ Ovarian } & Nanogels & $\begin{array}{l}\text { Paclitaxel } \\
\text { Cisplatin }\end{array}$ & A2780 & Nanogel $=3.0 \mu \mathrm{M}$ FA-nanogel $=1.4 \mu \mathrm{M}$ & [10] \\
\hline & Liposomes & Carboplatin & IGROV-1 & $\begin{array}{c}\text { Free Carboplatin }=40 \mu \mathrm{M} \text { FA- } \\
\text { Liposomes }=13.1 \mu \mathrm{M}\end{array}$ & [11] \\
\hline & Micelles & Paclitaxel & Hela & NA & [12] \\
\hline Cervix & $\begin{array}{c}\text { Gelatin } \\
\text { nanoparticles }\end{array}$ & Cisplatin & Hela & $\begin{array}{c}\text { Free cisplatin }=38.4 \mu \mathrm{M} \text { Nanoparticles }= \\
16.8 \mu \mathrm{M} \text { FA-Nanoparticles }=14.9 \mu \mathrm{M}\end{array}$ & [13] \\
\hline
\end{tabular}

Table1: Effect of folic acid decorated (FA) nanomedicines in breast, ovarian and cervix carcinomas.

NA: non available. 


\section{Advances in Pharmacology and Clinical Trials}

\section{Cervix Cancer}

Folic acid conjugated nanomedicines has also reported to increase the efficacy of paclitaxel and cisplatin in cervix cancer cells facilitating the intracellular uptake. In vitro studies in Hela cells (FR- $\alpha$ positive) have demonstrated that paclitaxel micelles [12] and gelatin nanoparticles loaded with cisplatin [13] and decorated with folic acid improve the inhibition of cell proliferation, increasing therapeutic efficacy. This inhibition improvement of folate decorated micelles of PTX was not observed in A459 lung adenocarcinoma cells (FR- $\alpha$ negative), showing a similar efficacy than non-targeted formulations and indicating that folic acid conjugation is the responsible of the enhancement of anticancer efficacy [13] (Table1).

\section{Conclusions}

Folic acid decorated nanomedicines have shown to increase the efficacy of several conventional anticancer drugs, such as taxanes and platinum based treatments, in breast, ovarian and cervix tumors, malignances that overexpress folic acid receptors. This improvement is due to a major uptake by cancer cells, getting a more selective location at the tumor mass; increasing antitumor efficacy and decreasing their adverse effects. In spite of the promising therapeutic of these folate-nanocarriers, the most of these systems have only been tested in vitro, and further research is necessary to investigate their effect using in vivo models.

\section{Acknowledgements}

Ana Isabel Fraguas (FPU14/06441) have been granted with a research fellow from the Spanish Ministry of Education.

\section{References}

1. Khodabandehloo H, Zahednasab H, Ashrafi Hafez A (2016) Nanocarriers Usage for Drug Delivery in Cancer Therapy. Iran J Cancer Prev 9(2): e3966.

2. Elkhodiry MA, Momah CC, Suwaidi SR, Gadalla D, Martins AM, et al. (2016) Synergistic Nanomedicine: Passive, Active, and Ultrasound-Triggered Drug Delivery in Cancer Treatment. J Nanosci Nanotechnol 16(1): 1-18.

3. Martin Sabroso C, Torres-Suarez AI (2013) Objective: tumor. Strategies of drug targeting at the tumor mass level. Clin Transl Oncol 16(1): 1-10.
4. Nicolas J, Mura S, Brambilla D, Couvreur P (2013) Design, functionalization strategies and biomedical applications of targeted biodegradable/biocompatible polymer-based nanocarriers for drug delivery. Chem Soc Rev 42(3): 1147-1235.

5. Tyagi S, Rawat S, Saxena S (2016) Folate conjugates: a boon in the anti-cancer therapeutics. International Journal of Pharmaceutical Sciences and Research 7: 4278-4303.

6. Erdogar N, Esendagli G, Nielsen TT, Şen M, Oner L, et al. (2016) Design and optimization of novel paclitaxel-loaded folate-conjugated amphiphilic cyclodextrin nanoparticles. Int J Pharm 509(1-2): 375-390.

7. Barbosa MV, Monteiro LO, Carneiro G, Malagutti AR, Vilela JM, et al. (2015) Experimental design of a liposomal lipid system: A potential strategy for paclitaxel-based breast cancer treatment. Colloids Surf B Biointerfaces 136: 553-561.

8. Wang F, Chen Y, Zhang D, Zhang Q, Zheng D, et al. (2012) Folate-mediated targeted and intracellular delivery of paclitaxel using a novel deoxycholic acid0-carboxymethylated chitosan-folic acid micelles. Int J Nanomedicine 7: 325-337.

9. Pawar H, Surapaneni SK, Tikoo K, Singh C, Burman R, et al. (2016) Folic acid functionalized long-circulating co-encapsulated docetaxel and curcumin solid lipid nanoparticles: In vitro evaluation, pharmacokinetic and biodistribution in rats. Drug Delivery 23(4): 1453-1468.

10. Desale SS, Soni KS, Romanova S, Cohen SM, Bronich TK, et al. (2015) Targeted delivery of platinum-taxane combination therapy in ovarian cancer. J Control Release 220: 651-659.

11. Chaudhury A, Das S, Bunte RM, Chiu GN (2012) Potent therapeutic activity of folate receptor-targeted liposomal carboplatin in the localized treatment of intraperitoneally grown human ovarian tumor xenograft. Int J Nanomedicine 7: 739-751.

12. Cheng LC, Jiang Y, Xie Y, Lu-Lu Qiu, Qing Yang, et al. (12017) Novel amphiphilic folic acid-cholesterolchitosan micelles for paclitaxel delivery, Oncotarget 8(2): 3315-3326. 


\section{Advances in Pharmacology and Clinical Trials}

13. Dixit N, Vaibhav K, Pandey RS, Jain UK, Katare OP, et al. (2015) Improved cisplatin delivery in cervical cancer cells by utilizing folate-grafted non-aggregated gelatin nanoparticles. Biomed Pharmacother 69: 1-10. 